\title{
The sensitivity of the uterus of the mouse and rat to intraluminal instillation
}

\author{
S. R. Milligan \\ Department of Physiology, King's College, Strand, London WC2R 2LS, U.K.
}

\begin{abstract}
Summary. The tissue accumulation of ${ }^{125} \mathrm{I}$-labelled human serum albumin $30 \mathrm{~min}$ after intravenous injection was used as an index of uterine vascular permeability. In ovariectomized mice, all sham and experimental instillation procedures produced a 6-10-fold increase in vascular permeability. Some effects were also manifest in the contralateral, control horn. In ovariectomized rats, instillation of saline and arachis oil increased vascular permeability 3-7-fold. After 3 or more days of progesterone treatment following oestradiol priming, fluorocarbon and arachis oil instillation produced marked vascular responses, but these were not restricted to the transient period in which the uterus would respond with decidualization. An IUD prevented the response to arachis oil instillation. These results indicate that the uterus is very sensitive to any manipulation and are consistent with decidualization representing a specialization of a normal uterine inflammatory response.
\end{abstract}

\section{Introduction}

One of the earliest recognizable maternal responses to the implantation of the blastocyst is a localized increase in uterine vascular permeability. This response forms the basis of the visualization of implantation sites by the 'blueing reaction': intravenously injected dyes (e.g. Pontamine sky Blue, Evans Blue) which bind to serum proteins rapidly accumulate in areas of high vascular permeability because of the protein leakage at these sites. The accumulation of dye can be readily identified macroscopically as 'blue spots' (Psychoyos, 1973).

The relationship between the increase in vascular permeability and the decidual transformation of the stromal cells is uncertain. The increase in vascular permeability at implantation sites precedes decidualization by some hours and it has been suggested that it is essential for the differentiation of the endometrial stromal cells into decidual cells (Psychoyos, 1973). In rats, the magnitude of the vascular permeability response to an artificial deciduogenic stimulus is closely related to the size of the decidual reaction induced (see Kennedy, 1979). This association between the increase in vascular permeability and the onset of decidualization has led to the implicit assumption that the initiating stimuli and hormone dependence of two responses may be similar. There have been some suggestions, however, that this may not be correct. In ovariectomized mice treated with progesterone alone, the intraluminal injection of oil will induce the vascular response but not decidualization (Milligan \& Mirembe, 1985). In rats, some small discrepancies between the relative magnitudes of the vascular response and the decidual response have been noted (Kennedy, 1980).

In terms of the ability of the uterus to mount a decidual cell response, there is a transient period of sensitivity to natural or artificial deciduogenic stimuli. The timing of this sensitive period is dependent on appropriate endocrine priming and, in intact mice, extends for a few hours over the normal time of implantation (Finn, 1977). Uterine sensitivity also can be induced in ovariectomized mice by the correct sequence of progesterone and oestradiol injections (Finn, 1966). The purpose of the present studies was to determine to what extent the response of increased vascular permeability after intraluminal instillation is limited to the particular endocrine states in which the uterus shows 
the potential for decidualization. The study was undertaken primarily on the mouse because the stimulus and endocrine requirements for the artificial induction of decidualization in this species are more specific than in the rat.

\section{Materials and Methods}

Animals. Adult Swiss albino female mice (A. Tuck \& Son Ltd, Battlesbridge, Essex, U.K.) weighing $20-30 \mathrm{~g}$ and rats (Charles River (U.K.) Ltd, Margate, Kent, U.K.) weighing 180-250 g were fed on a pelleted diet (41 B Oxoid) and housed at $21^{\circ} \mathrm{C}$ with lights on from 08:00 to $24: 00 \mathrm{~h}$. Females were ovariectomized using ether anaesthesia at least 2 weeks before use. Injections of oestradiol-17 $\beta$ and progesterone (Sigma Chemical Co. Ltd, Poole, Dorset, U.K.). were given subcutaneously in $0.1 \mathrm{ml}$ arachis oil (British Drug Houses Ltd, Poole, Dorset, U.K.). The first day of steroid treatment was designated as Day 1.

Intrauterine instillations into one uterine horn and/or manipulation of the control horn were performed using ether anaesthesia. Instillations were made via a 27 -gauge needle at the anterior tip of the uterine horn. In untreated ovariectomized females, the volume instilled was $5 \mu \mathrm{l}$; in all other females, the volume was $10 \mu \mathrm{l}$. In most experiments, the contralateral horn was untouched and served as a control. Sham-instillation involved handling and puncturing the tip of the uterus, but without any instillation. When appropriate, decidual cell responses were assessed by comparing the weights of control and instilled horns 2 days after instillation.

The materials instilled into the uterus were (a) a buffered saline $\left(147 \mathrm{~mm}-\mathrm{NaCl}, 4 \mathrm{~mm}-\mathrm{KCl}, 2 \mathrm{~mm}-\mathrm{CaCl}_{2}\right.$, 5 mM-Hepes, pH 7.4), (b) arachis oil (BDH Ltd), (c) a non-toxic fluorocarbon oil, Flutec PP5 (I.S.C. Chemicals Ltd, Bristol, U.K.), or (d) cholera toxin (Sigma) $2 \cdot 5 \mu \mathrm{g}$ in $10 \mu \mathrm{l}$ saline.

Estimation of vascular permeability. A quantitative index of the permeability of the uterine vasculature to large molecules was obtained from the leakage of radiolabelled albumin from the circulation (Arvidson, 1977; Milligan \& Mirembe, 1985). To avoid complications arising from vascular responses due to the trauma of the instillation procedure itself, the anterior half of each uterine horn was not included in the assessment of vascular permeability. In non-traumatized uteri, anterior and posterior portions of each uterine horn gave identical estimates for vascular permeability (personal observation).

Using ether anaesthesia, the external jugular was exposed and injected with $0.5-1.0 \mu \mathrm{Ci}^{125} \mathrm{I}$-labelled human serum albumin (HSA). At $30 \mathrm{~min}$ after this injection, a blood sample $(\sim 200 \mu \mathrm{l})$ was taken from the suborbital canthal sinus, again using ether anaesthesia. The blood sample was centrifuged to provide a $100-\mu l$ plasma sample. The females were killed by cervical dislocation immediately after the blood sample had been obtained. The lower half of each uterine horn was removed, rinsed in $0.154 \mathrm{M} \cdot \mathrm{NaCl}$, gently blotted and weighed. Radioactivity in tissue and plasma samples was determined using a Nuclear Enterprises automatic gamma counter. Tissue ${ }^{125} I$ counts were expressed as: (tissue ${ }^{125}$ I c.p.m./mg)/(plasma ${ }^{125}$ I c.p.m./ $/ \mathrm{ll}$ ).

On the assumption that all ${ }^{125} I$ in the tissue is protein bound, the tissue content of ${ }^{125} I$ depends on both the volume of blood within the tissue and the leakage of ${ }^{125}$ I-labelled HSA into the extravascular space (i.e. vascular permeability). Previous studies on the uterus (Milligan \& Mirembe, 1984, 1985) have suggested that the blood volume of the uterus is very much smaller than the albumin space (after a circulation time of $30 \mathrm{~min}$ ) and that the extravascular albumin space is the prime and overwhelming determinant of the total tissue albumin space. In view of this, the tissue concentration of ${ }^{125}$ I-labelled HSA can be taken to reflect the accumulation of albumin in the extravascular space and provides an index of vascular permeability.

Experimental treatments. A standard schedule was used in all experiments. The intraluminal or sham instillation was performed 3-4 h after the last steroid injection (except for Treatments (g) and (h) in Exp. 1, when there was a gap of $24 \mathrm{~h}$ ) and $6 \mathrm{~h}$ before death. The intravenous injection of ${ }^{125}$ I-labelled HSA was given $5.5 \mathrm{~h}$ after the intraluminal instillation and the tissue content of ${ }^{125} \mathrm{I}$ was assessed after a further $30 \mathrm{~min}$.

Experiment 1. Uterine vascular permeability was assessed in ovariectomized mice subject to one of the following treatments $6 \mathrm{~h}$ before death: (a) untreated; (b) laparotomy, but without disturbing either uterine horn; (c) sham instillation into one uterine horn; (d) instillation of saline into one uterine horn; (e) instillation of arachis oil into one uterine horn; (f) subcutaneous injection of $100 \mathrm{ng}$ oestradiol-17ß; (g) instillation of arachis oil into one uterine horn, $24 \mathrm{~h}$ after the last of two daily injections of $100 \mathrm{ng}$ oestradiol-17ß; (h) as (g), but with no instillation.

In additional untreated ovariectomized females, oil or saline containing suspended carbon particles was injected into one uterine horn. The animals were killed $15 \mathrm{~min}$ after instillation to assess the extent to which the injected material crossed to the contralateral horn.

Experiment 2. Uterine vascular permeability was assessed in ovariectomized rats subject to one of the following treatments: (a) untreated; (b) sham instillation into one uterine horn; (c) instillation of saline into one uterine horn; (d) instillation of arachis oil into one uterine horn.

Experiment 3. Uterine vascular permeability was assessed at various times during the following regimen of hormone treatment. Ovariectomized mice were primed with $100 \mathrm{ng}$ oestradiol-17及 (s.c.) for 3 days. After a further 2 days with no steroid treatment, females were treated daily with either (i) a combination of progesterone (1 mg) and oestradiol- $17 \beta(10 \mathrm{ng})$ to produce a transient period of maximal sensitivity to deciduogenic stimuli on the 3rd day (Finn \& Martin, 1972), or (ii) progesterone (1 mg s.c.) alone (in the absence of small amounts of oestradiol oil is 
ineffective as a deciduogenic stimulus). The steroids were given daily at $08: 00 \mathrm{~h}$. From Day 4 onwards, females received daily injections of progesterone alone or progesterone plus oestradiol. The experimental conditions for each treatment group are given in Table 1. Intrauterine instillations were performed on the last day of steroid treatment indicated. In some groups, the effectiveness of the instillation procedure in inducing decidualization was assessed after continuing progesterone treatment ( $1 \mathrm{mg}$ daily) for a further 2 days.

Experiment 4. At the time of ovariectomy, a silk thread (to serve as an IUD) was inserted into the top half of each uterine horn of some of the mice in this experiment. At 2 weeks after ovariectomy, all mice were primed with $100 \mathrm{ng}$ oestradiol- $17 \beta$ for 3 consecutive days per week for the next 3 weeks: this schedule allows the full development of the potential IUD effect (Martin \& Finn, 1979). At the beginning of the 4th week the females received 3 daily injections of progesterone ( $1 \mathrm{mg}$ ) and oestradiol $(10 \mathrm{ng})$. Vascular permeability was assessed in groups of animals with and without an IUD present, and with and without intrauterine instillation. Vascular permeability was also assessed in the upper portions of the uterine horns bearing an IUD. In another treatment group, the effectiveness of the IUD in inhibiting decidualization was assessed $48 \mathrm{~h}$ after arachis oil instillation into one uterine horn.

To examine whether the instilled oil was lost rapidly from the uterus when an IUD was present, oil containing suspended carbon particles was injected into one uterine horn of additional females. The animals were killed $6 \mathrm{~h}$ after instillation and the uteri examined.

The ability of the IUD to prevent pregnancy was tested in intact mice bearing unilateral IUDs. Control $(N=9)$ and IUD-bearing $(\mathrm{N}=10)$ mice were examined for the presence of implantation sites 7 days after mating.

Analysis of results. Results were analysed using Student's paired or unpaired $t$ tests, or analysis of variance followed by Duncan's New Multiple Range Test ( $\mathrm{Li}, 1957)$ as appropriate.

\section{Results}

\section{Experiment 1: the effect of intrauterine instillation and/or ostradiol-17\% treatment on uterine vascular} permeability in ovariectomized mice

All procedures that involved any kind of handling of the uterus of ovariectomized mice (untreated with steroids) produced a dramatic increase in the index of vascular permeability in the experimental horn (Fig. la). The magnitude of this response approached that obtained after the s.c. injection of $100 \mathrm{ng}$ oestradiol-17 $\beta$ (Fig. $1 \mathrm{~b}$ ). There were no significant differences between the effects of sham, saline or oil instillation $(\mathrm{F}=2 \cdot 07$, d.f. $=2,14, P>0.05)$.

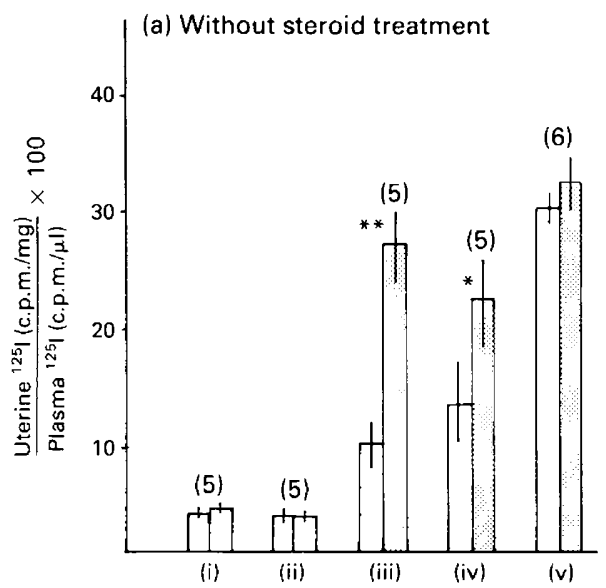

(b) After oestradiol-17ß

(7)

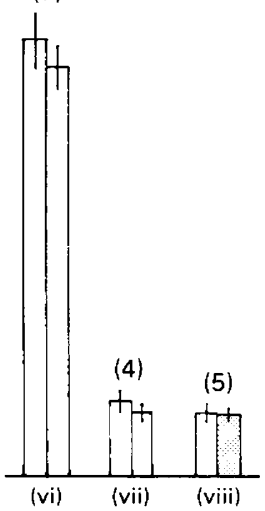

Fig. 1. Uterine accumulation of ${ }^{125} \mathrm{I}$-labelled human serum albumin as an index of vascular permeability in ovariectomized mice (a) without steroid treatment, and (b) after oestradiol-17 $\beta$ injections (Exp. 1). Values are means \pm s.e.m. of control horns (open bars) and experimental horns (stippled bars) for the no. of animals in parentheses. Intrauterine instillations were performed $6 \mathrm{~h}$ before death. Only the lower half of each uterine horn was taken for assessment of vascular permeability. (i) No instillation; (ii) laparotomy only; (iii) no instillation and sham instillation; (iv) no instillation and saline instillation; (v) no instillation and oil instillation; (vi) no instillation, $6 \mathrm{~h}$ after $100 \mathrm{ng}$ oestradiol-17及; (vii) no instillation; (viii) no instillation and oil instillation-(vii) and (viii) $24 \mathrm{~h}$ after last of two daily injections of $100 \mathrm{ng}$ oestradiol-17 $\mathrm{f}$. Values significantly different from corresponding control horn: ${ }^{*} P<0.05,{ }^{*} P<0.01$. 
All the experimental procedures involving any kind of handling of the uterus also produced significant increases in the vascular permeability of the untreated, contralateral, control horn. The response of the control horn after just sham instillation indicates that at least some of this response is not dependent on the actual instillation itself. After saline and oil injection, however, the instilled material was present throughout the lumen of the control horn within $15 \mathrm{~min}$ of instillation and this cross-over of material may have provided an additional stimulus to the control horn.

In contrast to the marked increase in vascular permeability at $6 \mathrm{~h}$ after s.c. oestradiol-17 $\beta$ treatment, uterine vascular permeability $30 \mathrm{~h}$ after the last of 2 daily injections of oestradiol-17 $\beta$ was only slightly, but significantly $(t=5 \cdot 24$, d.f. $=9, P<0.01)$, higher than in untreated animals. Arachis oil instillation into these oestradiol-primed uteri had no effect on the experimental or control horn (Fig. 1b).

Experiment 2: the effect of intrauterine instillation or uterine vascular permeability in overiectomized rats

The instillation of oil or saline increased vascular permeability in the instilled horns (Fig. 2). Neither of these treatments, nor sham instillation, produced any significant response in the contralateral control horn.

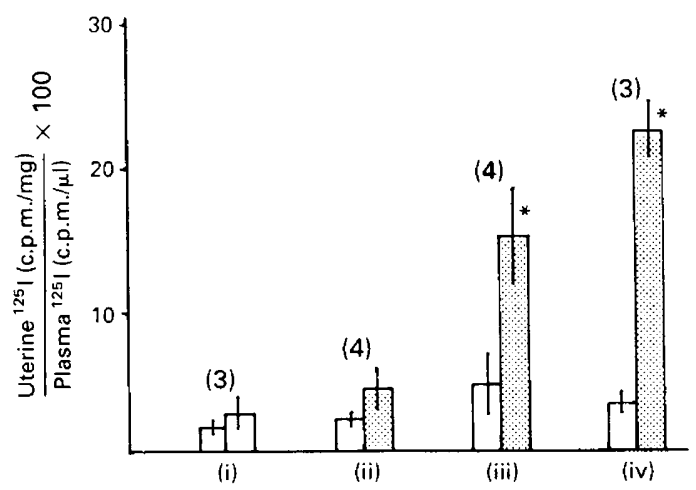

Fig. 2. Uterine accumulation of ${ }^{125} \mathrm{I}$-labelled human serum albumin as an index of vascular permeability in ovariectomized rats (Exp. 2). Values are means \pm s.e.m. of control horns (open bars) and experimental horns (stippled bars) for the no. of animals in parentheses. Intrauterine instillations were performed $6 \mathrm{~h}$ before death. Only the lower half of each uterine horn was taken for assessment of vascular permeability. (i) No instillation; (ii) no instillation and sham instillation; (iii) no instillation and saline instillation; (iv) no instillation and oil instillation. Values significantly different from corresponding control horn: $P<0.05$.

Experiment 3: the effect of intrauterine instillation procedures on uterine vascular permeability in mice primed with oestradiol and then treated with progesterone alone or progesterone plus oestradiol

On the 1 st and 2 nd days of progesterone plus oestradiol treatment, the instillation of arachis oil produced no significant effect on vascular permeability in either the instilled or control horn (Table 1; Treatments A-D). After the induction of sensitivity to deciduogenic stimuli with 3 days of progesterone plus oestradiol treatment (Treatments F-J), sham instillation produced a small rise in vascular permeability, but there was no significant response to saline instillation. In contrast, the instillation of arachis oil, fluorocarbon oil or cholera toxin all produced a marked increase 
Uterine sensitivity to intraluminal instillation
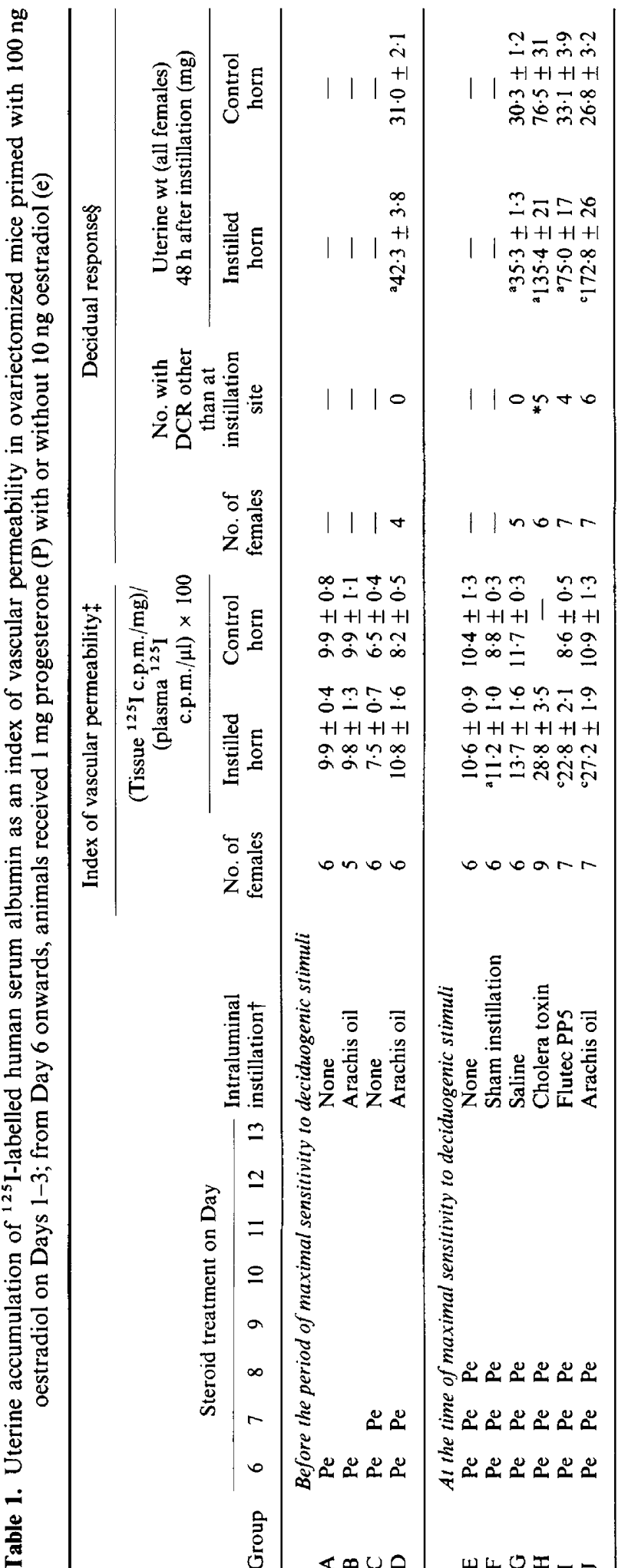

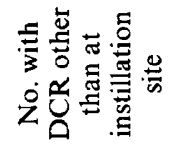

$1 \mid 0 \approx+\infty$

110000

1001

幽

Z

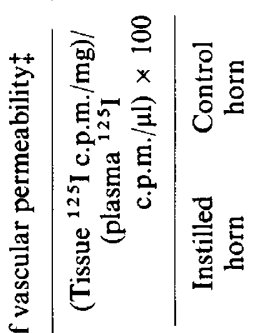

I Inorr

$1000 n$

$\dot{i} \dot{0} \ddot{0} \ddot{0}$

ஒே்

$3+1$
$+1+1+1$

$+1+1+11+1+1$

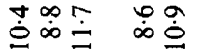

부ㅇㅛㅛ

$\dot{0} \dot{\dot{\varphi}} \dot{\varphi} \ddot{\dot{m}} \dot{\boldsymbol{n}}$

$+1+1+1+1+1+1$

+ọog

$+1+1+1+1+1+1$

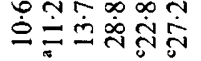

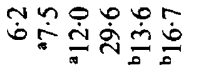

$\mid \ln \theta$

$\infty r \div \div n$

$+1+1+1+1+1$

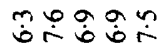

$\dot{N}+\pi+\infty$

$+1+1+1+1$

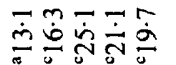

它总

on 0

bovarn

$\sin a r 0$

o or $\infty$

吾

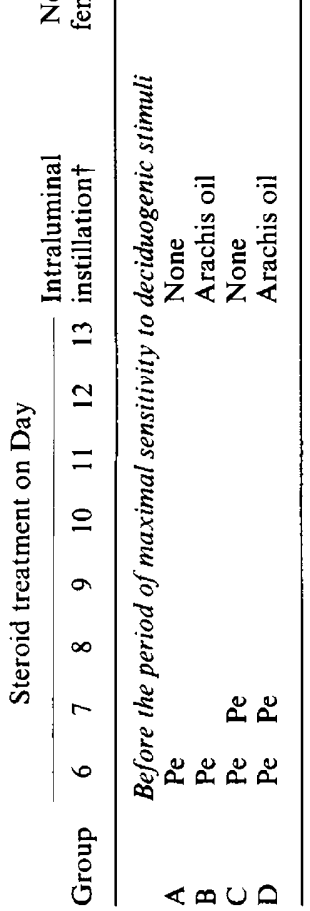

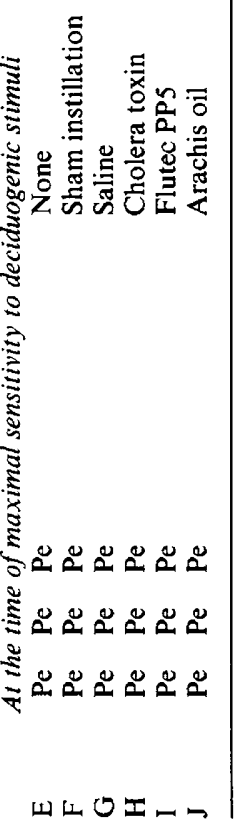

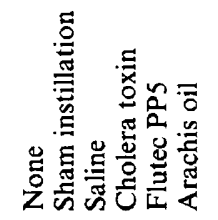

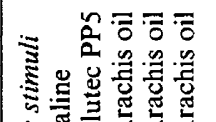

(2)

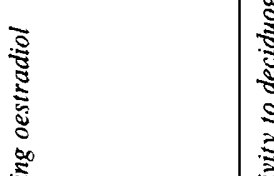

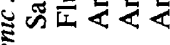

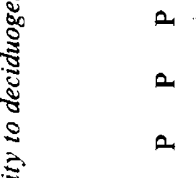

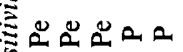

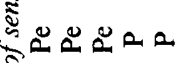

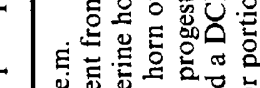

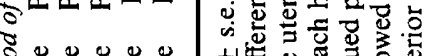

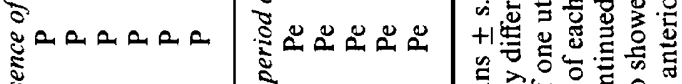

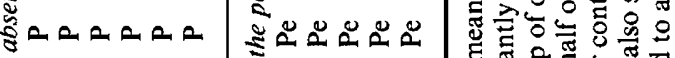

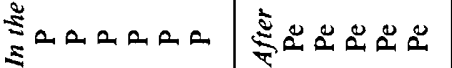


in vascular permeability in the instilled horn. These treatments also resulted in large decidual responses extending the length of the instilled horn. The smaller number of animals showing large decidual responses after the instillation of the fluorocarbon oil may reflect its low viscosity and more rapid loss from the uterus: when the uterus was ligated to prevent any loss through the cervix, $3 / 8$ females showed large decidual responses, with the weights of control and instilled horns being $25.6 \pm 1.6$ and $174.3 \pm 13.5 \mathrm{mg}$, respectively.

In the absence of oestradiol sensitization (Treatments $\mathrm{K}-\mathrm{P}$ ), the instillation of arachis or fluorocarbon oil, cholera toxin and saline all produced a marked increase in vascular permeability in the instilled horn. Decidual responses, however, were poor and mainly limited to the site of injection. The decidual response to cholera toxin was greater than that of other treatments, but was still limited to the anterior portion of the uterine horns.

Although the instillation of potential deciduogenic stimuli on the $3 \mathrm{rd}$ day of progesterone plus oestradiol treatment induced decidualization, the ability to show this response was lost on later days of treatment (Treatments Q-U). Despite this, the uteri in Treatments Q-U still showed large increases in vascular permeability after the instillation of arachis oil, fluorocarbon oil and saline.

\section{Experiment 4: the effect of an IUD on uterine vascular permeability and decidualization}

The presence of an IUD in the upper half of the uterine horn produced only a small local increase in vascular permeability (Fig. 3). The lower portion of the uterus showed no increase in vascular permeability after oil instillation, despite the fact that intraluminal oil was still present in all the females examined $6 \mathrm{~h}(\mathrm{~N}=5)$ after instillation.

With the presence of an IUD in one uterine horn, only $3 / 10$ females became pregnant; all implantation sites were in the horn contralateral to the IUD. In contrast, $9 / 9$ females without an IUD showed implantation sites in both uterine horns.

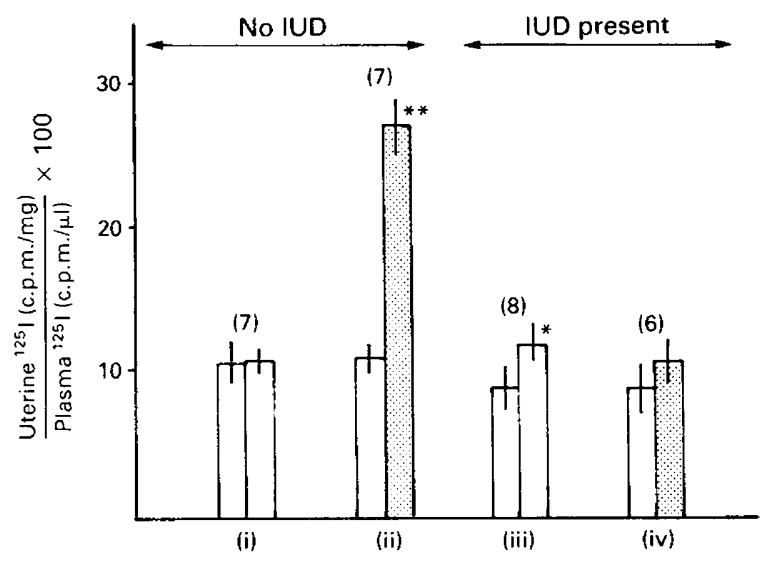

Fig. 3. The effect of an IUD on the uterine accumulation of ${ }^{125}$ I-labelled human serum albumin (an index of vascular permeability) (Exp. 4). Values are mean \pm s.e.m., for the no. of animals in parentheses. When present, IUDs (silk thread) were in the top half of both uterine horns. Ovariectomized mice were primed with oestradiol and progesterone according to the regimen that normally induces maximal sensitivity to deciduogenic stimuli. Uteri were subject to no instillation (open bars) or instillation of arachis oil (stippled bars) $6 \mathrm{~h}$ before death. Usually only the caudal half of each uterine horn was taken for assessment of vascular permeability. (i) no instillation; (ii) no instillation and oil instillation; (iii) caudal half of uterus (left column) and rostral half (with IUD) of uterus (right column); (iv) no instillation and oil instillation. Values significantly different from corresponding control horn: ${ }^{*} P<0.05 ;{ }^{*} P<0.01$. 


\section{Discussion}

These experiments indicate that the phenomenon of increased uterine vascular permeability after intraluminal instillation is not restricted to the transient period of uterine sensitivity to deciduogenic stimuli and may occur independently of the process of decidualization. An increase in vascular permeability may be obtained under a variety of conditions and the response is dependent both on the endocrine state of the uterus and the treatment to which it is subjected.

In the mouse, the uterus of ovariectomized animals is particularly sensitive (Exp. 1): all experimental manipulations produced large increases in vascular permeability and the magnitude of these responses was only slightly smaller than that induced by acute oestradiol treatment. Part of the response of ovariectomized females may reflect the sensitivity of the uterus to the physical trauma associated with instillation. The direct effects of trauma at the site of instillation were excluded in all the present experiments, however, by taking only the lower half of each uterine horn for the assessment of the vascular response. More indirect effects, perhaps due to traction during the instillation of the short uterus of ovariectomized animals, would explain the responses of the lower halves of the sham-instilled and contralateral control horns. The rapid transfer of materials between these horns may have also contributed to the response of the control horn after saline or oil instillation. In rats, in which there is no continuity between the two horns (Marston \& Kelly, 1969), saline and oil instillation only affected the injected horn (Exp. 2).

The degree of continuity between the lumina of the two uterine horns of mice seems to undergo subtle changes: in contrast to the findings in ovariectomized females, instilled materials rarely cross to the contralateral horn after oestradiol and progesterone treatment (Martin \& Finn, 1979; unpublished observation). The relative independence of the two horns after progesterone plus oestradiol treatment is reflected by the generally isolated response of the instilled horn. When an IUD is present, however, there is still sufficient continuity for the IUD usually to exert a bilateral effect (Exp. 4; Doyle \& Margolis, 1966).

The effects of instillation into the mouse uterus varied with the endocrine state of the animal. Despite the marked response of ovariectomized females, there was no reaction after oestradiol treatment for 2 days (Exp. 1) or on the 1st or 2nd day of combined progesterone and oestradiol treatment after oestradiol priming (Exp. 3). A vascular response became evident again after 3 or more days of progesterone treatment (whether or not combined with small amounts of oestradiol). The vascular response at this time, however, was not related to the ability of the uterus to show decidualization: potential deciduogenic stimuli induced the vascular response both in the absence of sensitizing oestradiol and after the end of the transient period of uterine sensitivity that is induced by oestradiol.

Although the effectiveness of IUDs has been linked with their ability to produce an inflammatory reaction (Greenwald, 1965), this was not reflected in any sustained, major increase in vascular permeability in the IUD-bearing uterus (Exp. 4). Martin \& Finn (1979) suggested that the failure of oil to induce decidualization in the presence of an IUD might be due to changes in myometrial activity and the premature loss of the oil stimulus from the uterus. This explanation would not account, however, for the failure of oil to induce the increase in vascular permeability that normally follows immediately after oil instillation (Exp. 4). Although Martin \& Finn (1979) observed that the oil had disappeared from most IUD-bearing uteri $44 \mathrm{~h}$ after injection, in the present study it was still evident at $6 \mathrm{~h}$. The complete failure of this oil to induce a vascular reaction suggests that the IUD-bearing uterus shows a general insensitivity to potential deciduogenic stimuli. This would also be consistent with the fact that there was little increase in uterine vascular permeability even in the region of the IUD thread itself.

The characteristics which determine the effectiveness of instilled materials to induce decidualization are uncertain. A wide variety of materials are able to induce the decidual cell reaction in mice, including arachis oil, beads of agar and air (Finn, 1977). In rats, the stimulus requirements would seem even less specific, with even saline producing some response (Finn \& Keen, 1963). Although 
the response to the non-toxic fluorocarbon oil (Flutec PP5) in the present study suggests that a physical stimulus alone is sufficient to induce the decidual cell reaction, this does not explain the ineffectiveness of plastic (McLaren, 1968) or glass beads (unpublished data). The surface properties of the instilled materials may be important in these cases.

The apparent sensitivity of the uterine vasculature to instillation procedures has important implications. Firstly, an increase in vascular permeability cannot be used as an index of the sensitivity of the uterus to potential deciduogenic stimuli: decidualization may follow the increase in vascular permeability, but this only occurs under specific endocrine conditions and after appropriate stimulation. Secondly, several authors have used intraluminal instillation (e.g. Pratt, 1977; Fishel, 1980), or luminal perfusion (Leese et al., 1979), as part of their protocol for examining the control and nature of uterine luminal constituents. The possibility that such procedures may induce vascular, inflammatory or other changes in uterine physiology, coupled with possible damage to the uterine luminal epithelium (Martin, 1984; Milligan \& Martin, 1984), may complicate the interpretation of such experiments.

The results from the present study would be consistent with the view that decidualization represents an extension of, and may have evolved from, the normal uterine inflammatory reaction (Finn, 1986). Vascular responses to trauma and instillation may occur in a wide variety of circumstances and this may reflect the general sensitivity of the uterus to physical and/or chemical stimulation. It could be envisaged that, under appropriate hormone conditions, such a general inflammatory response may develop further into a fully fledged decidual reaction. This idea would also be consistent with the fact that it has proved impossible to study the induction of decidualization separately from the vascular responses: all procedures that induce decidualization produce the increase in vascular permeability and all stimuli that induce the vascular response in appropriately sensitized uteri also produce decidualization (Exp. 3). Prostaglandins and cyclic AMP have been strongly implicated as potential mediators of these responses, but their precise role is still unclear (Milligan \& Lytton, 1983; Kennedy, 1984). To what extent the transient period of hormone-induced sensitivity to deciduogenic stimuli is dependent on qualitative and/or quantitative changes in the production of (Kennedy, 1983), or sensitivity to (Kennedy et al., 1983), such stimuli remains to be clarified.

I thank Colin Torrance for assistance, Colin Finn for helpful discussion, and the Wellcome Trust and Medical Research Council for financial support of this project.

\section{References}

Arvidson, N.G. (1977) Early oestrogen-induced changes in uterine albumin exchange in mice. Acta physiol., scand. 100, 325-331.

Doyle, L.L. \& Margolis, A.J. (1966) The effect of an IUCD on reproduction in mice $J$. Reprod. Fert. 11, 27-32.

Finn, C.A. (1966) Endocrine control of endometrial sensitivity during the induction of the decidual cell reaction in mice. $J$. Endocr. 36, 239-248.

Finn, C.A. (1977) The implantation reaction. In Biology of the Uterus, pp. 245-308. Ed. R. M. Wynn. Plenum Press, New York.

Finn, C.A. (1986) Implantation, menstruation and inflammation. Biol. Rev. (in press).

Finn, C.A. \& Keen, P.M. (1963) The induction of deciduomata in the rat. J. Embryol. exp. Morph. 111, $673-682$.

Finn, C.A. \& Martin, L. (1972) Endocrine control of the timing of endometrial sensitivity to a decidual stimulus. Biol. Reprod. 7, 82-86.
Greenwald, G.S. (1965) Interruption of pregnancy in the rat by a uterine suture. J. Reprod. Fert. 9, 9-17.

Fishel, S.B. (1980) Radiolabelled uterine proteins during early pregnancy and pseudopregnancy in mice after ovariectomy and superovulation. J. Reprod. Fert. 59, $473-478$

Kennedy, T.G. (1979) Prostaglandins and increased endometrial vascular permeability resulting from the application of an artificial stimulus to the uterus of the rat sensitized for the decidual cell reaction. Biol Reprod. 20, 560-566.

Kennedy, T.G. (1980) Estrogen and uterine sensitization for the decidual cell reaction: role of prostaglandins. Biol. Reprod. 23, 955-962.

Kennedy, T.G. (1983) Prostaglandin $\mathrm{E}_{2}$, adenosine $3^{\prime}: 5^{\prime}$ cyclic monophosphate and changes in endometrial vascular permeability in rat uteri sensitized for the decidual cell reaction. Biol. Reprod. 29, 10691076.

Kennedy, T.G. (1984) Embryonic signals and the initiDownloaded from Bioscientifica.com at 04/26/2023 12:08:38PM 
ation of blastocyst implantation. Aust. J. biol. Sci. 36, 531-543.

Kennedy, T.G., Martel, D. \& Psychoyos, A. (1983) Endometrial prostaglandin $\mathbf{E}_{2}$ binding: characterization in rats sensitized for the decidual cell reaction and changes during pseudopregnancy. Biol. Reprod. 29, 556-564.

Leese, H.J., Aldridge, S. \& Kiernan, T. (1979) Glucose movement into rat uterine fluid. J. Reprod. Fert. 56, $615-618$.

Li, J.C.R. (1957) Introduction to Statistical Inference. Edward Brothers, Ann Arbor.

Marston, J.H. \& Kelly, W.A. (1969) The effect of uterine anastomosis on the action of an intra-uterine device in the rat. $J$. Endocr. 43, 95-103.

Martin, L.M. (1984) On the source of uterine luminal proteins in the mouse. $J$. Reprod. Fert. 71, 73-80.

Martin, L. \& Finn, C.A. (1979) Varying effects of an IUD on decidualization in mice. $J$. Reprod. Fert. 55, 125-133.

McLaren, A. (1968) Can beads stimulate a decidual response in the mouse uterus? J. Reprod. Fert. 15, 313-315.

Milligan, S.R. \& Lytton, F.D.C. (1983) Changes in prostaglandin levels in the sensitized and non-sensitized uterus of the mouse after the intrauterine instillation of oil or saline. J. Reprod. Fert. 67, 373-377.
Milligan, S.R. \& Martin, L.M. (1984) The resistance of the mouse uterine lumen to flushing and possible contamination of samples by plasma and interstitial fluid. J. Reprod. Fert. 71, 81-87.

Milligan, S.R. \& Mirembe, F.M. (1984) Time course of the changes in uterine vascular permeability associated with the development of the decidual cell reaction to ovariectomized, steroid-treated rats. $J$. Reprod. Fert. 70, $1-6$.

Milligan, S.R. \& Mirembe, F.M. (1985) Intraluminally injected oil induces changes in vascular permeability in the 'sensitized' and 'non-sensitized' uterus of the mouse. J. Reprod. Fert. 74, 95-104.

Pratt, H.P.M. (1977) Uterine proteins and the activation of embryos from mice during delayed implantation. J. Reprod. Fert. 50, I-8.

Psychoyos, A. (1973) Endocrine control of egg implantation. In Handbook of Physiology, Section 7, Vol. II, Part 2, pp. 187-215. Eds R. O. Greep, E. G. Astwood \& S. R. Geiger. Am. Physiol. Soc., Washington, D.C.

Received 31 May 1986 